05

\title{
Физико-механические свойства модельного материала с топологией трижды периодических поверхностей минимальной энергии типа гироид в форме куба
}

\author{
(C) С.В. Дьяченко, Л.А. Лебедев, М.М. Сычев, Л.А. Нефедова
}

Санкт-Петербургский государственный технологический институт (технический университет), 190013 Санкт-Петербург, Россия

ООО «СЗРЦ Концерна ВКО «Алмаз-Антей»,

192012 Санкт-Петербург, Россия

e-mail: samyon2008@yandex.ru

(Поступило в Редакцию 14 ноября 2017 г.)

\begin{abstract}
Приведены результаты исследования физико-механических свойств материала, изготовленного из полилактида, с топологией трижды периодических поверхностей минимальной энергии. Образцы получены методом наплавления на $3 D$-принтере типа FDM в форме куба, который состоял из повторяющихся элементов с минимально возможной площадью. При сравнении экспериментальных деформационных кривых выявлено, что при нагружении в разном направлении относительно оси построения изделий полученные кривые качественно отличаются друг от друга, так как один и тот же материал ведет себя и как хрупкий, и как пластичный. Установлено различие величины удельного предела прочности $\left(\sigma_{\mathrm{sp}}, \mathrm{MPa} \cdot \mathrm{cm}^{3} / \mathrm{g}\right)$ в зависимости от направления нагрузки: перпендикулярно оси построения 7.6, по оси построения 11.3 , по оси построения с пластинами на двух гранях 27.6. Проведенная работа является подготовительной для разработки периодических структур на основе керамик, которые могут быть использованы в качестве защитных слоев техники.
\end{abstract}

DOI: 10.21883/JTF.2018.07.46169.2555

\section{Введение}

Изделия с топологией трижды периодической поверхности минимальной энергии (ТППМЭ) состоят из повторяющихся элементов с минимально возможной площадью [1]. Они сочетают поверхности с положительной и отрицательной кривизной. Примером таких поверхностей являются гироиды (рис. 1) - бесконечные, трижды периодические структуры (с периодичностью вдоль трех осей). Они имеют строгое математическое уравнение, с помощью которого можно варьировать параметры периодичности, а следовательно, и свойства получаемых материалов:

$$
\cos (x) \cdot \sin (y)+\cos (y) \cdot \sin (z)+\cos (z) \cdot \sin (x)=t .
$$

Конструкционными аналогами ТППМЭ являются бионические структуры, которые встречаются в природе поверхностные покровы жуков и бабочек, в липидных бинарных слоях и блок-сополимерах (рис. 2). Поверхности типа гироида обнаружены в мембранах хлоропластов и в кутикулярных образованиях на крыльях бабочек. Известно, что такие объекты сочетают низкую массу и высокие удельные механические характеристики [2].

Поэтому искусственно созданные структуры ТППМЭ могут заменить монолитные изделия и использоваться во многих отраслях. Например, за счет такой структуры можно создавать элементы, в которых будут происходить поглощение и угасание акустических волн; или использовать в качестве элементов катализатора для проведения гетерогенных химических процессов. Также такие системы имеют потенциал использования при создании изделий, подвергающихся экстремальным нагрузкам. В космической отрасли такого рода изделия могут применяться как амортизаторы для энергопоглощения, в качестве защитных слоев в посадочных системах космических аппаратов [3,4], заменив используемые пенопласты и сотоблоки из металлической фольги (рис. 3). В оборонной технике - в качестве защитных слоев и бронепреград, заменяя традиционные конструкции из полимеров, металлов и керамики.

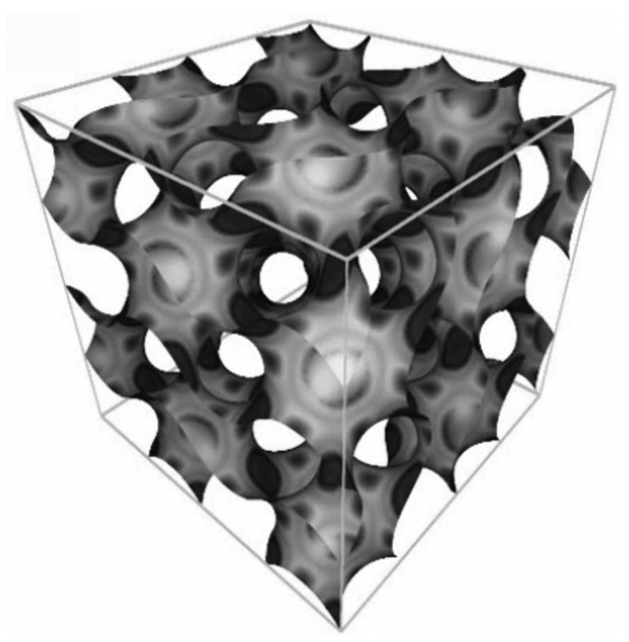

Рис. 1. Структура с топологией ТППМЭ - гироид [1]. 

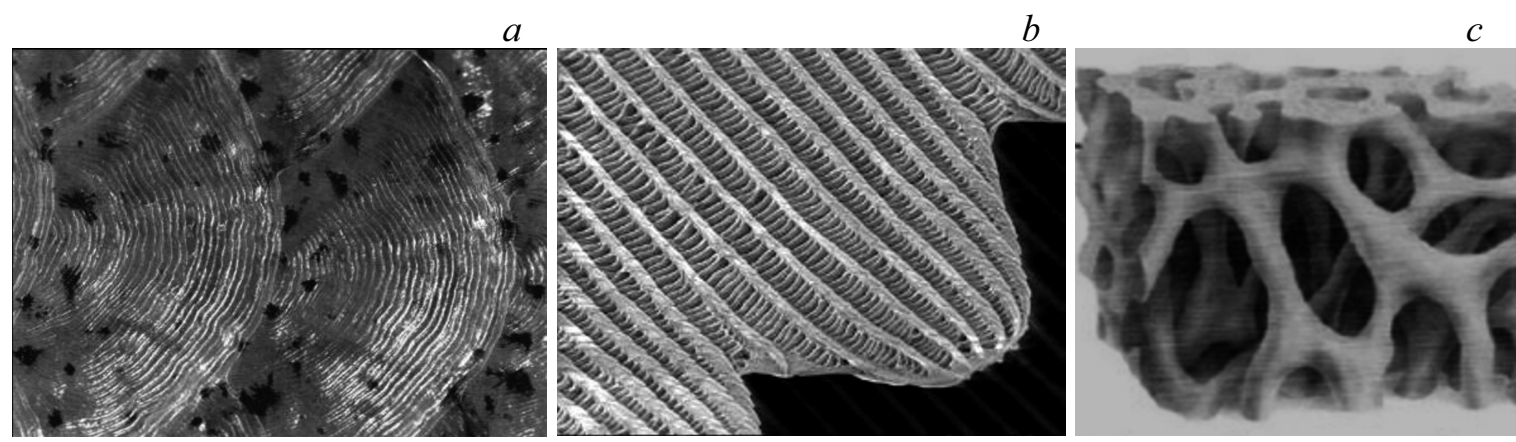

Рис. 2. $a, b, c$ - виды бионических структур - аналоги периодических структур в природе.


Рис. 3. $a, b-$ виды исполнения сотовых конструкций.

Широкое и перспективное использование ТППМЭ можно обеспечить применением в качестве защитных слоев, изготовленных из керамики. В последние десятилетия керамические материалы находят все большее применение для защиты личного состава и военной техники [5-7]. В частности, изделия, изготовленные из модифицированных оксида алюминия, карбида кремния и бора. На основе структур ТППМЭ предлагается создать конструкцию, обладающую повышенной стойкостью к нагрузкам и сниженной массой по сравнению с монолитными бронеплитками простых форм, что в соответствии с теорией разрушения бронепреград академика РАН В.Я. Шевченко должно обеспечивать увеличение диссипации энергии пули или снаряда за счет отклонения от линейной траектории, дробления и вращения.

Однако изготовление изделий с топологией ТППМЭ из керамики осложнено ценой этих материалов и проблемами создания. Поэтому в настоящей работе для исследования физико-механических свойств образцов они были изготовлены из пластика методом $3 D$-печати. Такой вариант изготовления является единственно приемлемым и позволяет удешевить стадию оптимизации топологии гироида перед изготовлением керамических изделий.

\section{Экспериментальная часть}

Для исследования физико-механических свойств были изготовлены образцы ТППМЭ с топологией гироида (рис. $4, a)$, состоящего из 8 элементарных ячеек. Образцы получены методом наплавления на $3 D$-принтере типа FDM модели Anet A6. Все изделия имели кубическую форму. Кроме того, были изготовлены образцы с двумя пластинами на противоположных гранях куба ТППМЭ (рис. $4, b$ ).


Рис. 4. Внешний вид образцов после печати: $a-$ гироид; $b$ - гироид с пластинами. 

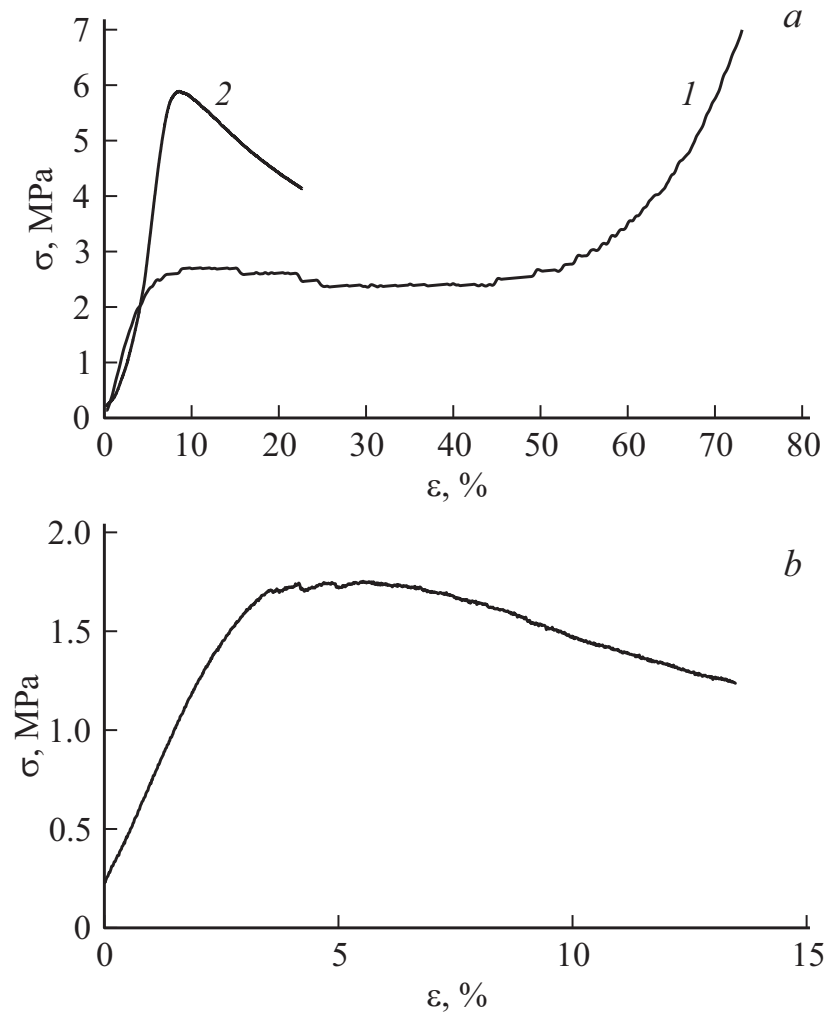

Pис. 5. Деформационные кривые образцов гироидов: $a-$ сжатие вдоль оси роста (кривая 1 - образцы без пластин, кривая 2 - образцы с пластинами); $b$ - перпендикулярно оси роста.

Полимерный материал образцов - полилактид (PLA), полиэфир молочной (2-гидроксипропионовой) кислоты. Благодаря наличию в своем составе сложноэфирной группы полилактид способен постепенно гидролизоваться. При гидролизе полилактида образуется молочная кислота, поэтому считается, что использование материалов на основе полилактида не наносит ущерб биосфере. Кроме этого, он дешев, нетоксичен и биосовместим с тканями человека [8].

Образцы испытывали на прочность на сжатие в соответствии с ГОСТ 4651-2014 на электромеханической машине марки Walter + bai с максимально возможной нагрузкой до $400 \mathrm{kH}$, при температуре воздуха $26^{\circ} \mathrm{C}$ и скорости нагружения $5 \mathrm{~mm} / \mathrm{min}$. Испытания проводились в двух направлениях - вдоль оси построения (роста) изделия и по нормали.

\section{Результаты исследования и их обсуждение}

На основании физико-механических испытаний для образцов ТППМЭ типа гироид были определены следующие параметры - размер ребра (1): $30 \mathrm{~mm}$, масса (m): $(6.0 \pm 0.5) \mathrm{g}$, кажущаяся плотность $(\rho): 0.21 \mathrm{~g} / \mathrm{cm}^{3}$. Для исследования влияния топологии на прочностные свой- ства образцы подвергались сжатию. При нагружении образцов вдоль оси роста изделия они в ходе эксперимента сжимались, практически не изменяя своей площади. При анализе деформационной кривой (рис. 5, $a$, кривая 1) определен средний предел прочности изделий $\sigma=(2.64 \pm 0.1) \mathrm{MPa}$, при пересчете в удельные единицы $\sigma_{\mathrm{sp}}=12.6 \mathrm{MPa} \cdot \mathrm{cm}^{3} / \mathrm{g}$. Значение деформации на сжатии при пределе прочности составило $\varepsilon_{\text {cy }} \approx 12.3 \%$. Представленная зависимость соответствует диаграмме сжатия пластичного материала с участками упругой, уплотнительно-пластической и пластической деформации. Поэтому здесь можно указать предельное значение деформации от начальных размеров - $\varepsilon_{\lim } \approx 51.9 \%$ (значение, при котором начинается экспоненциальный рост функции, а материал при этом уплотняется).

При нагружении перпендикулярно направлению оси роста образцы растрескивались, происходило смещение и увеличение их площади. При анализе деформационной кривой (рис. $5, b)$ определен средний предел прочности изделий $\sigma=(1.75 \pm 0.2) \mathrm{MPa} \mathrm{или} \sigma_{\mathrm{sp}}=8.4 \mathrm{MPa} \cdot \mathrm{cm}^{3} / \mathrm{g}$, при этом $\varepsilon_{\text {cy }} \approx 5 \%$. Представленная зависимость соответствует диаграмме сжатия хрупкого материала.

Кроме того, исследовалось влияние нагрузки на образец, изготовленный с пластинами на двух гранях, ограничивающих расползание несвязанных концов структуры, как показано на рис. 4, $b$. При нагружении такого образца вдоль оси роста механизм деформации изменился, а именно закрепление краев привело к растрескиванию материала (аналогично эффекту при нагружении образца перпендикулярно оси роста), что характерно при сжатии хрупкого материала. При анализе деформационной кривой (рис. 5, $a$, кривая 2) определен средний предел прочности изделия $\sigma=(5.8 \pm 0.1) \mathrm{MPa} \mathrm{или}$ $\sigma_{\mathrm{sp}}=27.6 \mathrm{MPa} \cdot \mathrm{cm}^{3} / \mathrm{g}$, при этом $\varepsilon_{\mathrm{cy}} \approx 7.5 \%$.

При сравнении полученных деформационных кривых можно отметить, что при нагружении в различном направлении относительно оси роста экспериментальные кривые качественно отличаются друг от друга, т.е. один и тот же материал ведет себя и как хрупкий, и как пластичный, наблюдается анизотропия физикомеханических свойств. Аналогичным полимерным материалом, у которого при изменении направления нагрузки меняется тип деформационной кривой (механизм разрушения), является дерево [9]. При воздействии нагрузки вдоль волокон тип деформационной кривой соответствует хрупкому материалу, а поперек - пластичному материалу (радиальное направление).

Количественно разницу образцов относительно оси роста можно проследить по изменению предела прочности и деформации при пределе прочности. Предел прочности при нагружении вдоль оси роста оказался выше на 40\%, чем при нагружении перпендикулярно оси, а при одном и том же направлении вдоль оси роста для образцов с пластинами предел оказался выше на $55 \%$, чем на открытом изделии. Однако наличие пластин на двух гранях изменяет тип деформации материала, делая его хрупче. Наибольшее значение $\varepsilon_{\text {cy }}$ (примерно 
в два раза выше относительно прочих) у образца, который испытывался вдоль оси роста. Следовательно, располагая образец гироида именно вдоль оси роста изделия относительно внешнего воздействия, его можно использовать в качестве энергопоглотителя ударной нагрузки.

\section{Заключение}

Получены образцы с топологией трижды периодической поверхности минимальной энергии типа гироид методом $3 D$-печати. На основании физико-механических испытаний определен предел прочности, который оказался выше при нагрузке вдоль оси роста, чем при ее перпендикулярном расположении, следовательно, в защитных слоях изделия нужно располагать вдоль оси построения. Наличие пластин на гранях куба, расположенных перпендикулярно нагрузке (аналог сандвич-панели), значительно увеличивает предел прочности, поэтому их наличие целесообразно для бронепреград.

Плотность образцов ТППМЭ типа гироида в 5-6 раз ниже, чем у сплошных литых образцов из такого же полилактида $\left(\rho=1.25 \mathrm{~g} / \mathrm{cm}^{3}\right)$, значит масса таких изделий при одинаковом размере и форме будет меньше, что позволит увеличить мобильность техники за счет снижения грузоподъемности и расхода топлива. Изготовленные изделия из пластика подходят для прямого использования в качестве амортизирующего слоя, который будет принимать ударную нагрузку при посадке космических аппаратов или при столкновении с метеоритами. Так, в работе [4] в качестве амортизирующего слоя испытывались конструкции, сделанные в виде сотовых элементов из алюминиевого сплава $\mathrm{AlSi}_{7} \mathrm{Mg}_{0.45}$. Такой материал обладает низкой плотностью и высокой деформацией при нагрузке. В этой работе приведены следующие параметры для сотового блока: $\rho=0.38 \mathrm{~g} / \mathrm{cm}^{3}, \sigma \approx 6 \mathrm{MPa}$, $\sigma_{\mathrm{sp}} \approx 15.8 \mathrm{MPa} \cdot \mathrm{cm}^{3} / \mathrm{g}, \quad \varepsilon_{\mathrm{lim}} \approx 55 \%, \quad \varepsilon_{\text {су }} \approx 5 \%$. Сравнив физико-механические свойства гироида и алюминиевого блока, можно заключить, что конструкции имеют идентичные параметры при сохранении у ТППМЭ меньшей массы и большего запаса величины упругой деформации при достижении предела прочности.

Для применения периодических структур типа гироид в качестве бронепреград в дальнейших исследованиях будут получены ТППМЭ из керамики. На первоначальных этапах с использованием традиционных технологий, когда с помощью $3 D$-печати будут изготовлены полимерные образцы ТППМЭ в негативе и залиты связующим для дальнейшего спекания и получения позитива нужной топологии из керамики. На последующих этапах - получение керамических изделий ТППМЭ непосредственно печатью. Кроме того, для увеличения стойкости таких бронепреград будет проведено заполнение пустот в структуре плотным полимером - полиуретаном. Такая структура будет представлять собой композит из двух взаимопроникающих фаз, выполненных из материалов с существенно отличающимся упругим импедансом.
Работа выполнена в рамках базовой части государственного задания Минобрнауки России № 10.8003.2017/8.9 по приоритетному направлению развития науки, технологий и техники.

\section{Список литературы}

[1] Лорд Э.Э., Маккей А.Л., Ранганатан С. Новая геометрия для новых материалов. М.: Физматлит, 2010. 264 с.

[2] Kovalev I. // Bulletin of the Entomological Society of Canada. 2005. Vol. 37. N 3. P. 140-142.

[3] Алешин В.Ф., Колобов А.Ю., Макаров В.П., Петров Ю.А. // Наука и образование: научно-техническое издание: Эл № ФС 77-30569. № 4. 2010. С. 1-7.

[4] Марков В.А., Пусев В.И., Селиванов В.В. // Вопросы оборонной техники. 2012. № 7-8. С. 54-62.

[5] Овсиенко А.М. и др. // Актуальные проблемы технологии производства современных керамических материалов. СПб., 2015. С. 84-93.

[6] Маликова E.B. и др. // Огнеупоры и техническая керамика. 2013. № 4-5. C. 35-39.

[7] Игнатова А.М., Сильников Н.М. // Вестник ПНИПУ. Машиностроение, материаловедение. 2015. Т. 17. № 1. C. 61-72.

[8] Sin L.T., Rahmat A.R., Rahman W.A. Polylactic Acid. PLA Biopolymer Technology and Applications. Elsevier Inc., 2012. $341 \mathrm{p}$.

[9] Потыкалова М.В., Мелехов В.И. Механические свойства древесины. Архангельск: Архан. гос. техн. ун-т., 2008. 31 с. 